\title{
The application of graphene in lithium ion battery electrode materials
}

\author{
Jiping Zhu*, Rui Duan, Sheng Zhang, Nan Jiang, Yangyang Zhang and Jie Zhu
}

\begin{abstract}
Graphene is composed of a single atomic layer of carbon which has excellent mechanical, electrical and optical properties. It has the potential to be widely used in the fields of physics, chemistry, information, energy and device manufacturing. In this paper, we briefly review the concept, structure, properties, preparation methods of graphene and its application in lithium ion batteries. A continuous 3D conductive network formed by graphene can effectively improve the electron and ion transportation of the electrode materials, so the addition of graphene can greatly enhance lithium ion battery's properties and provide better chemical stability, higher electrical conductivity and higher capacity. In this review, some recent advances in the graphene-containing materials used in lithium ion batteries are summarized and future prospects are highlighted.
\end{abstract}

Keywords: Graphene; Lithium ion battery; Electrode materials; Electrochemical characterizations

\section{Introduction}

Nowadays, ever-increasing demands on energy have driven many countries to invest heavily in finding new sources of energy or investigating new ways/devices to store energy (Zhu et al. 2014). A kind of energy storage device is lithium ion batteries, which have many unique advantages in comparison to conventional batteries. These merits include high open-circuit voltage, high energy density, long useful life, no memory effect, no pollution and low self-discharge rate. The advantageous properties of lithium ion batteries make them quickly become the new generation of secondary batteries in recent years and they are now widely used in mobile phones, laptops and other portable electronic devices (Tarascon \& Armand 2001). In lithium ion batteries, lithium ions move from the negative electrode to the positive electrode during discharge, and this is reversed during the charging process. Cathode materials commonly used are lithium intercalation compounds, such as $\mathrm{LiCoO}_{2}$, $\mathrm{LiMn}_{2} \mathrm{O}_{4}$ and $\mathrm{LiFePO}_{4}$; anode materials commonly used are graphite, tin-based oxides and transition metal oxides. However, these materials have some drawbacks that limit their use. For example, carbon materials have good cycle performance but low initial charge and discharge

\footnotetext{
* Correspondence: jpzh@ustc.edu.cn

School of Materials Science and Engineering, Hefei University of Technology, Hefei, Anhui 230009, P R China
}

efficiency; tin-based oxides have good cycle but high irreversible capacity loss in the first cycle (Simon \& Gogotsi 2008). One of the potential solutions to these problems is to develop new electrode materials for lithium ion batteries. Graphene, a miracle material, is chemically stable and has high electrical conductivity. So it has naturally been considered as a suitable electrode alternative in the battery applications (Atabaki \& Kovacevic 2013).

Graphene is a monolayer of graphite, consisting of $\mathrm{sp}^{2}$ hybridized carbon atoms arranged in a honeycomb crystal lattice (Geim \& Novoselov 2007), as shown in Figure 1. It is a two-dimensional material, meaning that every atom of graphene can be considered as a surface atom. Graphene forms the basic structure of other carbon materials like graphite, carbon nanotubes and fullerenes. In 2004, Andre Geim and Kostya Novoselov obtained graphene via a simple method (Novoselov et al. 2004), which subsequently attracted attention around the world, owing to graphene's novel structure and properties. For example, this two-dimensional carbon material has a specific surface area of $2600 \mathrm{~m}^{2} / \mathrm{G}$ (Stoller et al. 2008) with its honeycomb structure potentially resulting in higher lithium storage capacity. Furthermore, its high electron mobility (15000 $\left.\mathrm{cm}^{2} /(\mathrm{V} \cdot \mathrm{s})\right)$, outstanding thermal conductivity $(3000 \mathrm{~W} /(\mathrm{m} \cdot \mathrm{K}))$ (Bolotin et al. 2008), good chemical stability and excellent mechanical properties make it an ideal target for forming composite materials used as the base

\section{空}




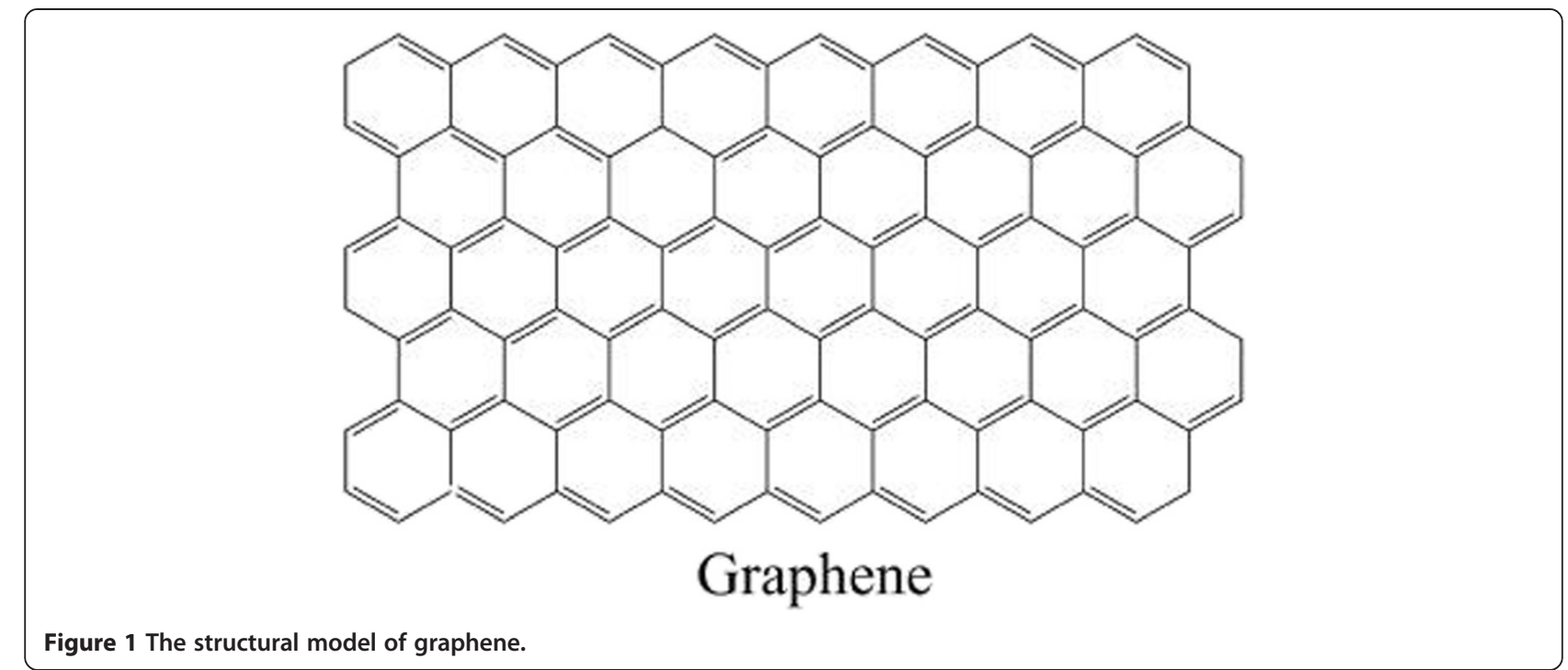

electrode. Improved electrodes also allow for the storage of more lithium ions and increase the battery's capacity. As a result, the life of batteries containing graphene can last significantly longer than conventional batteries (Bolotin et al. 2008). In the conventional lithium ion batteries, as lithium ions are inserted and removed from the electrode materials, the materials will swell and shrink, leading to a quicker breakdown. This can be avoided through the addition of graphene, whose efficient conductivity can lead to less resistive heating within the electrode, so batteries can operate at lower temperatures, which ultimately improves the battery's safety (Atabaki \& Kovacevic 2013). Graphene has many additional properties such as the quantum hall effect, bipolar field-effect, ferromagnetism, superconductivity and high electron mobility (Katsnelson et al. 2006). These properties make graphene suited for use in many fields. Moreover, recent scientific advances have allowed for the development of various low-cost and simple methods of preparing graphene. This is particularly important for large-scale production and applications. Below, a review of the applications of graphene and graphene-based composites as electrode materials in lithium ion batteries are analyzed, as well as likely paths for future development.

\section{Preparation methods of graphene}

Graphene are currently produced by several different methods: micromechanical exfoliation of highly oriented pyrolytic graphite with or without previous processing of the surface (Tang \& Hu 2012; Lu et al. 1999; Fredriksson et al. 2009), epitaxial growth (Yu et al. 2011; Berger et al. 2006), chemical vapor deposition (CVD) (An et al. 2011; Wintterlin \& ML 2009) and reduction of graphene oxide (GO) (Li et al. 2008; Gómez-Navarro et al. 2007; Stankovich et al. 2007; Mattevi et al. 2009; Fernandez-
Merino et al. 2010). The graphene produced by micromechanical exfoliation and chemical vapor deposition shows good monolayer morphology. However these methods are complex and can only produce small amounts of grapheme, hence are not suitable for mass production and application. Chemical reduction of graphene oxide is currently the most suitable method for large-scale graphene production. So graphene used in the vast majority of lithium ion battery electrode materials is obtained by reducing GO.

Graphene oxide is produced from natural graphite through the Hummers method (Fan et al. 2008; GómezNavarro et al. 2007), Brodie method (Brodie \& Chim 1860) or Staudenmaie method (Staudenmaier \& Deut 1898). The Hummers method is most commonly used. Once GO is produced, hydrazine hydrate, $\mathrm{NaBH}_{4}$ (Shin et al. 2009) or other reducing agents are used to produce graphene. This mode of preparation is simple and will enable mass production of graphene. The shortfall of this method is that introduced oxygen will affect the produced graphene's electrochemical properties, resulting in deterioration of graphene. Despite these drawbacks, chemical reduction of GO is still the primary method used by researchers, owing to its simplicity and lower equipment burden.

\section{Graphene in lithium ion battery cathode materials}

Some of the most commonly studied cathode materials used in lithium ion batteries (LIBs) are $\mathrm{LiCoO}_{2}, \mathrm{LiMn}_{2} \mathrm{O}_{4}$, $\mathrm{LiFePO}_{4}$ and $\mathrm{Li}_{3} \mathrm{~V}_{2}\left(\mathrm{PO}_{4}\right)_{3}$. These materials have electronic conductivities of $10^{-4} \mathrm{~S} / \mathrm{cm}$ (Dokko et al. 2001; Barker et al. 1996; Levasseur et al. 2002), $10^{-6} \mathrm{~S} / \mathrm{cm}$ (Marzec et al. 2002; Cao \& Prakash 2002), $10^{-9} \mathrm{~S} / \mathrm{cm}$ (Prosini et al. 2002; Shi et al. 2003) and $2.4 \times 10^{-7} \mathrm{~S} / \mathrm{cm}$ (Pan et al. 2011) respectively. These electronic conductivity values are fairly 
low when high battery performance is required, so electron conducting additives are frequently added to such materials in order to improve their electrochemical properties.

Existing studies show that pure graphene can't become a direct substitute for current carbon-based commercial electrode materials in lithium ion batteries due to its low coulombic efficiency, high charge-discharge platform and poor cycle stability (Atabaki \& Kovacevic 2013). However, when used as a matrix in the composite electrode materials, graphene can play a very important role.

In recent years, researchers have begun to study graphene modified for use as a cathode material and have found that it can significantly improve cathode electrochemical performance (Geim \& Novoselov 2007). For example, the two-dimensional large surface area and superior electron transfer capability of graphene can effectively improve the transmission and diffusion abilities of electron and ion in cathode materials.

\subsection{Lithium metal oxide-graphene composites as cathode materials for LIBs}

$\mathrm{LiMn}_{2} \mathrm{O}_{4}$ is used as cathode electrode material, owing to its low cost, environmental friendliness and high abundance (Manev et al. 1995). However, its low electrical conductivity results in a low-rate capacity. Published papers have demonstrated that graphene sheets are effective agents for improving their conductivity and rate capacity. $\mathrm{LiMn}_{2} \mathrm{O}_{4}$-graphene composites with high rate capacity were synthesized by a microwave assisted hydrothermal method (Bak et al. 2011). The composites exhibited reversible capacities of $117 \mathrm{mAh} / \mathrm{g}$ and $101 \mathrm{mAh} / \mathrm{g}$ at $50 \mathrm{C}$ and $100 \mathrm{C}$. In another study, $\mathrm{LiMn}_{2} \mathrm{O}_{4}$-graphene composites were synthesized by self-assembly approach combined with a solid-state lithiation method (Zhao et al. 2011). The enhancement in electrochemical properties is attributed to the superior $\mathrm{Li}^{+}$diffusion kinetics and improved stability across a wide voltage range in crystalline $\mathrm{LiMn}_{2} \mathrm{O}_{4}$-graphene composites. Furthermore, their capacities approached the theoretical value and the cycling stability was enhanced.

$\mathrm{LiNi}_{1 / 3} \mathrm{Mn}_{1 / 3} \mathrm{Co}_{1 / 3} \mathrm{O}_{2}$ is a promising candidate for cathode electrode materials. It shows high energy density, good stability, enhanced safety and can be produced at low cost (Zhu et al. 2012). However, cation disorder occurs during calcination and results in deterioration of its kinetic properties. To improve its electrochemical performance, $\mathrm{LiNi}_{1 / 3} \mathrm{Mn}_{1 / 3} \mathrm{Co}_{1 / 3} \mathrm{O}_{2}$-graphene composites are prepared as cathode materials for LIBs. Jiang and coworkers reported that $\mathrm{LiNi}_{1 / 3} \mathrm{Mn}_{1 / 3} \mathrm{Co}_{1 / 3} \mathrm{O}_{2}$-graphene composites prepared by mechanical mixing could deliver a capacity of $115 \mathrm{mAh} / \mathrm{g}$ at $6 \mathrm{C}$ (Jiang et al. 2012). $\mathrm{LiNi}_{1 / 3} \mathrm{Mn}_{1 / 3} \mathrm{Co}_{1 / 3} \mathrm{O}_{2}$-graphene composites prepared by micro-emulsion and ball-milling route could deliver a reversible capacity of $150 \mathrm{mAh} / \mathrm{g}$ at $5 \mathrm{C}$, much higher than that of bare $\mathrm{LiNi}_{1 / 3} \mathrm{Mn}_{1 / 3} \mathrm{Co}_{1 / 3} \mathrm{O}_{2}$ (Rao et al. 2011). The improved performance is attributed to grain connectivity and high electronic conductivity.

\subsection{LiMPO$_{4}$-graphene composites as cathode materials for LIBs}

When used as an electrode material, $\mathrm{LiFePO}_{4}$ has the advantages of high specific capacity $170 \mathrm{mAh} / \mathrm{g}$, low cost and low toxicity (Kobayashi et al. 2009). However, its low electrical conductivity $\left(10^{-9} \mathrm{~S} / \mathrm{cm}^{2}\right)$ and poor lithium ion diffusion $\left(10^{-14}-10^{-16} \mathrm{~cm}^{2} / \mathrm{S}\right)$ lead to capacity fade quickly under high rate charge and discharge (Amin \& Maier 2008). The decision to add graphene to improve the electric properties of the phosphate was based on following premises. Firstly, graphene's high conductivity could enhance the conductance of electrode materials. Secondly, the mechanical properties of graphene could help maintain the microstructure of the phosphate and improve cyclic stability. Indeed, for the $\mathrm{LiFePO}_{4} /$ graphene composite material, the flexible mesh structure of graphene improved its electrical conductivity and ratio performance. The $\mathrm{LiFePO}_{4} /$ graphene nanocomposite was prepared by various synthesis routes, with hydrothermal, solvothermal and solid state routes (Amin \& Maier 2008). In addition, the researcher also generated $\mathrm{LiFePO}_{4}$ (LFP) nanoparticles, mixed them with graphite oxide in solution. The mixed solution was then underwent a spray-dried and sintered process to obtain the $\mathrm{LiFePO}_{4} /$ graphene composite (LFP/G) shown in Figure 2. The result showed that graphene well coated the surface of the LiFePO , with a thickness of approximately $2 \mathrm{~nm}$ (about 3-5 layers of graphene) and formed a continuous lamellar structure; $\mathrm{LiFePO}_{4}$ nanoparticles had uniform size at 2-5 nm. The obtained material displays a more regular morphology and structure, which can potentially lead to a large enhancement of conductivity. In addition, this material can be further carbon coated to obtain carbon coated $\mathrm{LiFePO}_{4} /$ graphene $(\mathrm{LFP} /(\mathrm{G}+\mathrm{C})$ ), which presents superior rate and cycle performances.

In comparison to $\mathrm{LiFePO}_{4}, \mathrm{Li}_{3} \mathrm{~V}_{2}\left(\mathrm{PO}_{4}\right)_{3}$ is an attractive cathode material for LIBs, because its average extraction/ reinsertion voltage is about $4.0 \mathrm{~V}$, and its theoretical capacity is $197 \mathrm{mAh} / \mathrm{g}$ (Huang et al. 2009; Yu et al. 2012). $\mathrm{Li}_{3} \mathrm{~V}_{2}\left(\mathrm{PO}_{4}\right)_{3}$ forms a monoclinic structure and has a high operating voltage and shows a good performance at high discharge currents. However, its intrinsic low electronic conductivity $\left(240 \mathrm{nS} / \mathrm{cm}\right.$ at $\left.25^{\circ} \mathrm{C}\right)$ limits its rate capacity, so graphene is added to improve its electrochemical performance. $\mathrm{Li}_{3} \mathrm{~V}_{2}\left(\mathrm{PO}_{4}\right)_{3} /$ graphene cathode material has been prepared by sol-gel, solid state and spray-drying synthesis methods (Huang et al. 2009; Yu et al. 2012). The product which was prepared by a sol-gel route shows excellent rate capacity and cycling stability (Yu et al. 2012). 

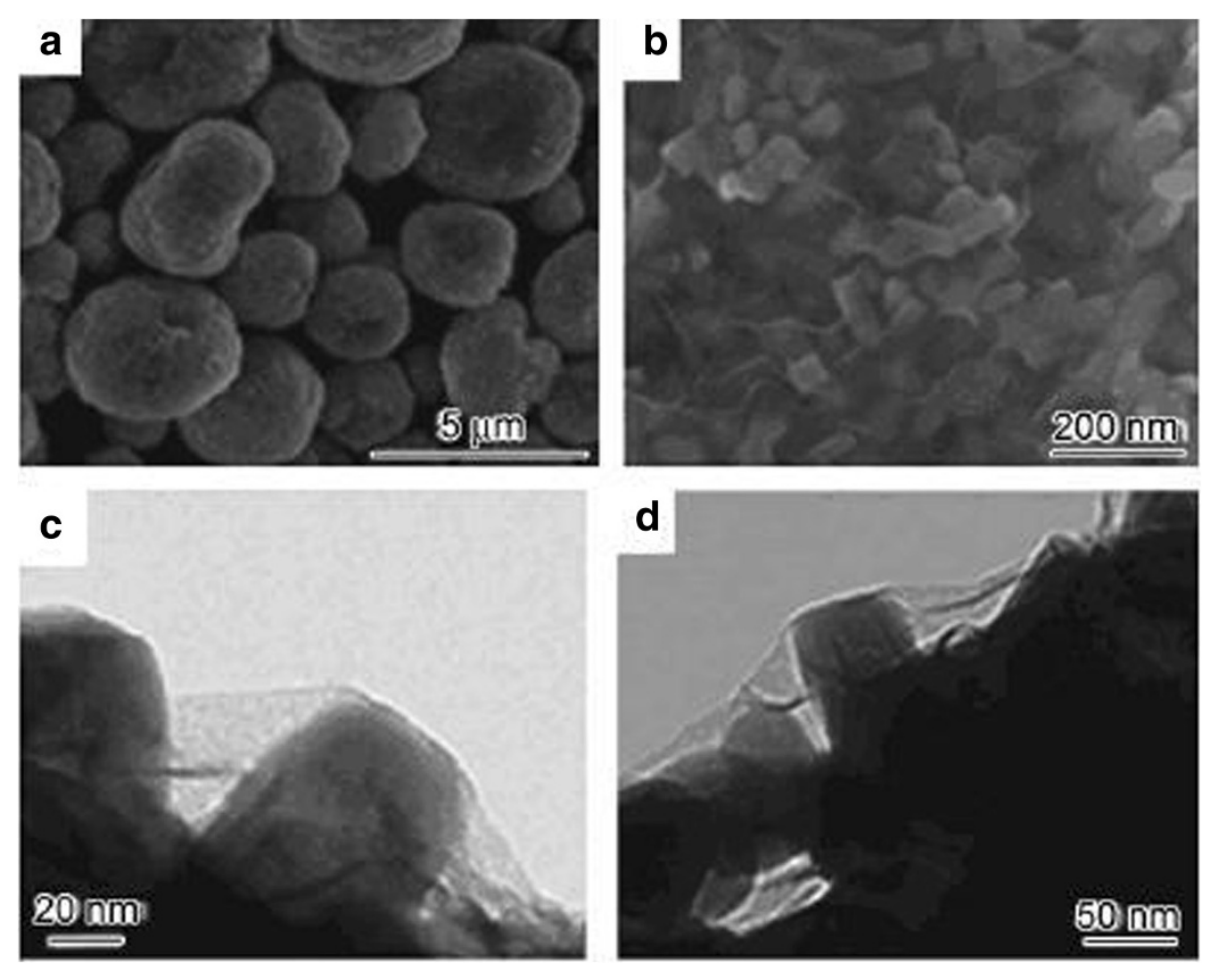

Figure 2 SEM and TEM images of the composite. (a, b) SEM images showing an overview of the LFP /G particles. (c) TEM image illustrating a local area of one LFP nanoparticle in an LFP/G secondary particle. (d)TEM image showing a local area of one LFP nanoparticle in an LFP/(G + C) secondary particle

\section{Graphene in lithium ion battery anode materials} Graphene has opened new possibilities in the field of lithium ion battery materials due to its light weight, high electrical conductivity, superior mechanical flexibility, and chemical stability (Su et al. 2012). These properties prove advantageous when graphene is used in the anode. The addition of graphene to anode materials has lead to superior electrical conductivity, high surface area (2620 $\mathrm{m}^{2} \mathrm{~g}^{-1}$ ), high surface-to-volume ratio, ultra-thin thickness which can shorten the diffusion distance of ions, structural flexibility that paves the way for constructing flexible electrodes, thermal and chemical stability which guarantee its durability in harsh environments.

At present, non-carbon-based lithium-ion battery anode materials are mainly tin-based electrode materials, as well as silicon-based and transition metal-based materials (Zhu et al. 2011; Liu et al. 2012; Wang et al. 2010a; Lian et al. 2010a; Tao et al. 2012; Wang et al. 2010b; Kim et al. 2012; Tung et al. 2009; Cai et al. 2012a; Wang et al. 2011a). Even though the aforementioned materials have high theoretical capacity, drawbacks to their use as anode materials are volume expansion during lithium/delithiation and a large internal stress. After repeated charging and discharging, the material is prone to rupture, resulting in poor cycling performance. To overcome these disadvantages, graphene is adopted. Table 1 summarizes LIB anode materials (non-carbon) doped with graphene. Some widely and commonly used materials are discussed in this paper.

\subsection{Graphene modified tin-based oxide}

$\mathrm{Sn}$ and their oxides such as $\mathrm{SnO}_{2}$ are exclusively studied as lithium ion battery anode materials. However, their use is limited by a defect, in that chemical reduction will often bring in electronic barriers to $\mathrm{Li}^{+}$repulsion. Lithiation and delithiation reactions $\left(\mathrm{Sn}+4.4 \mathrm{Li}^{+}+4.4 \mathrm{e}^{-} \leftrightarrow \mathrm{Li}_{4.4} \mathrm{Sn}\right)$ can cause large volume changes. This leads to the pulverization of the particles and the electrical disconnection of the electrode. In order to circumvent this, new anode materials with graphene have been examined in many recent studies. For example, the performance of anode electrode was improved when tin nanoparticles embedded in grapheme was used (Liang et al. 2011).

The graphene matrix not only can accommodate the volume change of Sn during charge-discharge, but also facilitate electron transport because of its high electronic conductivity. To prepare this type of anode, it is essential to use hydrothermal synthesis and subsequent annealing. It is reported that the reversible specific capacity of the nanocomposite is $662 \mathrm{mAhg}^{-1}$ at a specific current of 
Table 1 Summary of LIB anode materials (non-carbon) containing graphene

\begin{tabular}{|c|c|c|c|c|}
\hline Anode materials & Structure & Synthesis method & Capacity and cycle performance & Reference \\
\hline $\mathrm{SnO}_{2} /$ graphene & orthorhombic & Hydrothermal & $\begin{array}{l}\text { First discharge capacity } 1588 \mathrm{mAhg}^{-1} \text {, } \\
\text { after } 40 \text { cycles remain } 730 \mathrm{mAh} / \mathrm{g}\end{array}$ & (Zhu et al. 2011) \\
\hline Si/graphene & Cubic diamond type & Hydrazine reduction & $\begin{array}{l}\text { First discharge capacity } 2753 \mathrm{mAhg}^{-1} \text {, } \\
\text { after } 50 \text { cycles remain } 590 \mathrm{mAh} / \mathrm{g}\end{array}$ & $\begin{array}{l}\text { (Liu et al. 2012; Wang et al. } \\
\text { 2010a) }\end{array}$ \\
\hline $\mathrm{CO}_{3} \mathrm{O}_{4} /$ graphene & spinel & Solvothermal & $\begin{array}{l}\text { First discharge capacity } 1826 \mathrm{mAhg}^{-1} \text {, } \\
\text { after } 40 \text { cycles maintain } 1310 \mathrm{mAh} / \mathrm{g}\end{array}$ & (Lian et al. 2010a) \\
\hline $\mathrm{Mn}_{3} \mathrm{O}_{4} /$ graphene & spinel & Hydrothermal & $\begin{array}{l}\text { First discharge capacity } 900 \mathrm{mAhg}^{-1} \text {, } \\
\text { after } 100 \text { cycles maintain } 390 \mathrm{mAh} / \mathrm{g}\end{array}$ & (Tao et al. 2012) \\
\hline CuO/graphene & sphalerite & $\begin{array}{l}\mathrm{N} \text {-methyl-2-p yrrolidone } \\
\text { solvent }\end{array}$ & $\begin{array}{l}\text { First discharge capacity } 640 \mathrm{mAhg}^{-1} \text {, } \\
\text { after } 50 \text { cycles maintain } 583.5 \mathrm{mAh} / \mathrm{g} \text {. }\end{array}$ & (Wang et al. 2010b) \\
\hline $\mathrm{Fe}_{3} \mathrm{O}_{4} /$ graphene & Trans spinel & Reduction & $\begin{array}{l}\text { First discharge capacity } 1426 \mathrm{mAhg}^{-1} \text {, } \\
\text { after } 100 \text { cycles maintain } 580 \mathrm{mAh} / \mathrm{g}\end{array}$ & (Kim et al. 2012) \\
\hline $\mathrm{TiO}_{2}$ /graphene & Rutile type & Gas/liquid interface reaction & $\begin{array}{l}\text { First discharge capacity } 499 \mathrm{mAhg}^{-1} \text {, } \\
\text { after } 10 \text { cycles maintain } 150 \mathrm{mAh} / \mathrm{g}\end{array}$ & (Tung et al. 2009) \\
\hline $\mathrm{CeO}_{2} /$ graphene & Face-centered cubic & Hydrothermal & $\begin{array}{l}\text { First discharge capacity } 1469 \mathrm{mAhg}^{-1} \text {, } \\
\text { after } 100 \text { cycles maintain } 605 \mathrm{mAh} / \mathrm{g}\end{array}$ & (Cai et al. 2012a) \\
\hline $\mathrm{SnS}_{2}$ /graphene & $\begin{array}{l}\text { Hexagonal crystal } \\
\text { structure }\end{array}$ & Solution phase method & $\begin{array}{l}\text { First discharge capacity } 1664 \mathrm{mAhg}^{-1} \text {, } \\
\text { after } 500 \text { cycles maintain } 600 \mathrm{mAh} / \mathrm{g}\end{array}$ & (Wang et al. 2011a) \\
\hline $\begin{array}{l}\mathrm{Fe}_{3} \mathrm{O}_{4}-\mathrm{SnO}_{2}-\mathrm{gra}- \\
\text { phene }\end{array}$ & -二-二- & $\begin{array}{l}\text { Gas-liquid interfacial } \\
\text { reaction }\end{array}$ & $\begin{array}{l}\text { First discharge capacity } 1740 \mathrm{mAhg}^{-1} \text {, } \\
\text { after } 115 \text { cycles maintain } 1198 \mathrm{mAh} / \mathrm{g}\end{array}$ & (Chang et al. 2012) \\
\hline $\mathrm{Li}_{4} \mathrm{Ti}_{5} \mathrm{O}_{12}$ /graphe-ne & Spinel & Sol-gel method & $\begin{array}{l}\text { First discharge capacity } 430 \mathrm{mAhg}^{-1} \text {, } \\
\text { after } 35 \text { cycles maintain } 150 \mathrm{mAh} / \mathrm{g}\end{array}$ & $\begin{array}{l}\text { (Lian et al. 2011; Choucair et al. } \\
\text { 2009a) }\end{array}$ \\
\hline
\end{tabular}

$100 \mathrm{mAg}^{-1}$ after 100 cycles, and $417 \mathrm{mAhg}^{-1}$ at the high current of $1000 \mathrm{mAg}^{-1}$ (Liang et al. 2011).

The $\mathrm{SnO}_{2}$ /graphene composite can also be synthesized by a simple hydrothermal method for high-capacity lithium storage. Flower-like $\mathrm{SnO}_{2}$ nanorod clusters with a size of $800 \mathrm{~nm}$ are the product of the synthesized process (Figure 3). The flower-like $\mathrm{SnO}_{2}$ /graphene composite shows a first discharge and charge capacity of $1588 \mathrm{mAhg}^{-1}$ and $1240 \mathrm{mAhg}^{-1}$ at the current density of $50 \mathrm{mAg}^{-1}$, respectively (Evanoff et al. 2011). After 40 cycles at different current densities of 50, 100, and 500 $\mathrm{mAg}^{-1}$, the reversible discharge capacity was still maintained at $730 \mathrm{mAhg}^{-1}$.

\subsection{Graphene-modified silicon-based materials}

As an anode material, silicon and lithium ions can form Li ${ }_{4.4} \mathrm{Si}$. The theoretical charge capacity of this compound is up to $4200 \mathrm{mAh} / \mathrm{g}$, it also has a low discharge voltage. However, a limitation to its use is its charge volume effect. During the discharge process, silicon and lithium form $\mathrm{Li}_{3.75} \mathrm{Si}$. As a result, $\mathrm{Si}$ volume increased up to $270 \%$. This leads to poor circulation stability (Wolfenstine 1999). The addition of Silicon nanomaterials and carbon-coating can buffer this volume expansion to some extent. When graphene is introduced, it can not only prevent silicon nanoparticles gathering but also improve the electron and lithium ions transport capability.

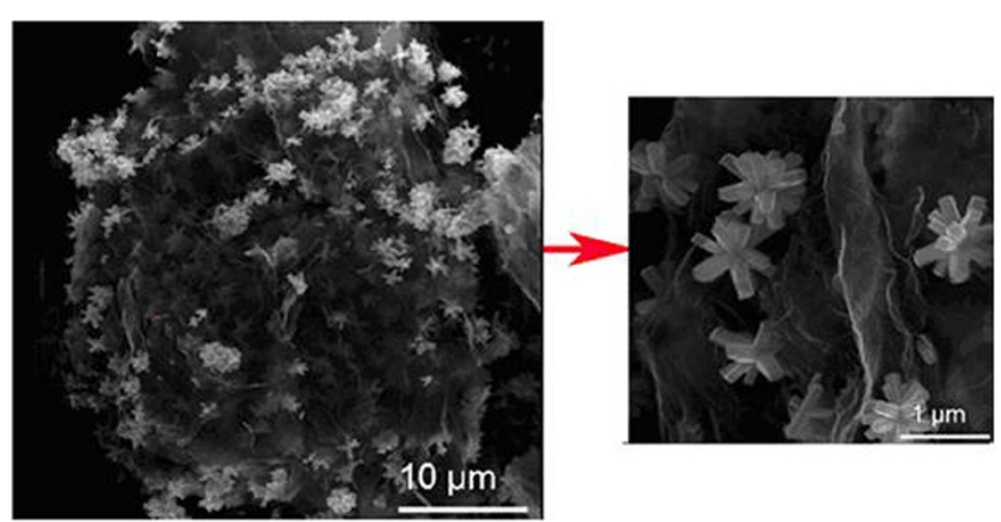

Figure $3 \mathrm{SEM}$ image of flower-like $\mathrm{SnO}_{2}$-graphene in different magnifications. 
Yushin etc. (Evanoff et al. 2011) used a vapor deposition method to form a continuous Si film on the graphene sheet surface. Following that, a high temperature treatment in propylene allowed the silicon surface to be coated with carbon. The obtained composite material showed enhanced conductivity as well as oxidation resistance. This composite has 3D porous structure, which buffer $\mathrm{Si}$ volume change during charge and discharge, owing to the presence of a stable solid electrolyte interface film. Furthermore, this composite has more than $1000 \mathrm{mAh} / \mathrm{g}$ specific delithiated capacity and good cycle stability under $1400 \mathrm{~mA} / \mathrm{g}$ current density.

\subsection{Graphene modified transition metal-based materials}

Transition metal oxides which have high lithium storage capacity are known as potential alternative anode materials for high capacity lithium ion batteries. Owing to the presence of volume changes during charge and discharge and their low conductivity, graphene can also be used to improve their electrochemical properties.

$\mathrm{Co}_{3} \mathrm{O}_{4}$ has a high theoretical capacity of $890 \mathrm{mAh} / \mathrm{g}$. However, the processes of charging and discharging cause large volume expansion. The addition of graphene can effectively improve $\mathrm{Co}_{3} \mathrm{O}_{4}$ electrochemical properties (Kim et al. 2011; Li et al. 2011; Yan et al. 2010; Wu et al. 2010; Yang et al. 2010). For example, at $200 \mathrm{~mA} / \mathrm{g}$ of current density, $\mathrm{Co}(\mathrm{OH})_{2}$ 's first cycle off-lithium specific capacity is $660 \mathrm{mAh} / \mathrm{g}$. Through synchronizing hydrothermal reduction with graphene, the material's delithiated specific capacity increases up to $1120 \mathrm{mAh} / \mathrm{g}$. After 30 cycles, the reversible capacity of the composite material remains $82 \%$ of the initial capacity.

$\mathrm{Mn}_{3} \mathrm{O}_{4}$ has a $936 \mathrm{mAh} / \mathrm{g}$ theoretical capacity. However, due to its poor electrical conductivity (about $10^{-7}-10^{-8} \mathrm{~S} /$ $\mathrm{cm})$, the actual capacity with Co doped can only reach a maximum of $400 \mathrm{mAh} / \mathrm{g}$. When the composite with graphene formed through a two-step liquid method, followed by hydrothermal synthesis, the delithiated ratio capacity of this compound is about $900 \mathrm{mAh} / \mathrm{g}$ at low current density (40 $\mathrm{mA} / \mathrm{g}$ ), closing to the theoretical capacity. When current density reaches $1600 \mathrm{~mA} / \mathrm{g}$, the specific capacity of this compound maintains $390 \mathrm{mAh} / \mathrm{g}$ (Wang et al. 2010c).

$\mathrm{CuO}$ has low band gap energy and high catalytic activity. However, as an anode material, it has a low conductive performance and large volume expansion effect. These shortcomings can be improved by forming $\mathrm{CuO}$ / graphene composites (Mai et al. 2011). First $\mathrm{CuO}$ and graphite oxide are used to produce $\mathrm{CuO} /$ graphene composite by hydrothermal synthesis, followed by a reduction process. After 50 cycles, the composite material's inverse capacity reached $583.5 \mathrm{mAh} / \mathrm{g}$ and the capacity retention ratio was $75.5 \%$.

$\mathrm{Fe}_{3} \mathrm{O}_{4}$ /graphene composites have excellent high-rate performance, except when prepared by gas-liquid interface method (Lian et al. 2010b). At $35 \mathrm{~mA} / \mathrm{g}$ current density, the specific reversible capacity holds at $1026 \mathrm{mAh} / \mathrm{g}$ (30 cycles). At $700 \mathrm{~mA} / \mathrm{g}$ current density, the capacity is still $580 \mathrm{mAh} / \mathrm{g}$ after 100 cycles. $\mathrm{Fe}_{2} \mathrm{O}_{3}$ is used as anode material owing to its high theoretical capacity (1005 $\mathrm{mAh} / \mathrm{g}$ ) and low price (Choucair et al. 2009a). (Wang et al. 2011b) prepared $\mathrm{Fe}_{2} \mathrm{O}_{3}$ /graphene composites by a hydrothermal method. The addition of graphene prevented $\mathrm{Fe}_{2} \mathrm{O}_{3}$ from aggregation and also buffered material's volume expansion. At $1160 \mathrm{~mA} / \mathrm{g}$ current density, the reversible capacity of the composite remains 660 $\mathrm{mAh} / \mathrm{g}$ after 100 cycles.

$\mathrm{TiO}_{2}$ with graphene is another nanocomposite that can be synthesized by a facile gas/liquid interface reaction (Cai et al. 2012a). The electrochemical performance tests show that the composite's specific charge capacity is 499 $\mathrm{mAh} \mathrm{g}^{-1}$ at a current density of $100 \mathrm{mAg}^{-1}$. This specific charge capacity drops to $150 \mathrm{mAhg}^{-1}$ at a high current density of $3000 \mathrm{mAg}^{-1}$. The advantage of this nanocomposite is that the oxygen-containing groups on the graphene sheets can be reduced after the heat treatment and residual functional groups including the $\mathrm{OH}$ and $\mathrm{COOH}$ on the surface of graphene sheets can strongly interact with the metal ions during the synthesis process .The random hybridization of $\mathrm{TiO}_{2}$ nanoparticles and ultrathin graphene sheets form a three-dimensional porous structure of the $\mathrm{TiO}_{2}$-graphene nanocomposite. The small nanoparticles provide a short mean-free-path for electron and lithium ion to travel during the lithium ion insertion/extraction process, resulting in excellent rate capability.

\section{Conclusion}

Compared to traditional carbon electrode materials, graphene, due to its low initial coulombic efficiency, high charge and discharge platform and other shortcomings, cannot directly replace traditional graphite as an anode material. However, graphene does demonstrate high electrical conductivity, good mechanical strength, excellent flexibility, great chemical stability and high specific surface area. This is especially noticeable when graphene is chemically converted with a greater proportion of functional groups, proving that it is suited for use as a base composite electrode material. When used as electrode material, graphene can effectively reduce the size of the active material, prevent agglomeration of nanoparticles, improve electrons and ions transmission capacity, as well as enhancing the electrode's mechanical stability. As a result, graphene-containing electrode materials have high capacity and good rate performance. Lithium metal oxide-graphene, $\mathrm{LiMPO}_{4}$-graphene, Tin-based, Si-based and transition metal based electrode materials with graphene have been extensively studied in this paper. The composite materials' advantages can be summarized as 
following. Firstly, graphene's flexibility makes it an ideal material to buffer metal electrode's volume expansion and contraction during the charge-discharge process. This improves the electrode material's cycle life performance. Further, the excellent electrical properties of graphene can enhance the conductivity of metal electrode material. Moreover, the addition of graphene can control the growth of metal oxide particles. Smaller particles means the diffusion distance of lithium ions and electrons is reduced, this improves the material's rate performance. Finally, the lithium storage capacity for most metal oxide composite materials with graphene has improved greatly.

In addition, various approaches are taken to prepare graphene. These vary from simple mechanical mixing to the well controlled in situ reactions and interfacial reactions, which result in better graphene morphology and structure. Developing easily replicable methods for producing graphene is the key to future application of graphene in lithium ion batteries.

\section{Competing interests}

The authors declare that they have no competing interests.

\section{Authors' contributions}

JZ and RD carried out the application of graphene studies, participated in the sequence alignment and drafted the manuscript. All authors read and approved the final manuscript.

\section{Acknowledgments}

We thank the national natural science foundations of China (No. 21373074), Anhui province science and technology plan (No. 11010202133) for their financial support.

Received: 22 July 2014 Accepted: 30 September 2014

Published: 8 October 2014

\section{References}

Amin R, Maier J (2008) Solid State lonics 178:1831-1836

An H, Lee WJJ, Jung J, Appl C (2011) Phys 11:S81-S85

Atabaki MM, Kovacevic R (2013) Electron Mater Lett 2:133-153

Bak SM, Nam KW, Lee CW, Kim KH, Jung HC, Yang XQ, Kim KB (2011) J Mater Chem 21:17309-17315

Barker J, Pynenburg R, Koksbang R, Saidi MY (1996) Electrochim Acta 41:24812488

Berger C, Song Z, Li X, Wu X, Brown N, Naud C, Mayou D, Li T, Hass J, Marchenkov AN, Conrad EH (2006) Science 312:1191-1196

Bolotin Kl, Sikes KJ, Jiang Z, Klima M, Fudenberg G, Hone J, Kim P, Stormer HL (2008) Solid State Commun 146:351-355

Brodie BC, Chim A (1860) Phys 59:466-472

Cai D, Lian P, Zhu X, Liang S, Yang W, Wang H (2012a) Electrochim Acta 74:65-72

Cao F, Prakash J (2002) Electrochim Acta 47:1607-1613

Chang K, Wang Z, Huang G, Li H, Chen W, Lee JY (2012) J Power Sources 201:259-266

Choucair M, Thordarson P, Stride JA (2009a) Nat Nanotech 4:30-33

Dokko K, Mohamedi M, Fujita Y, Itoh T, Nishizawa M, Umeda M, Uchida I (2001) Electrochem Soc 148:A422-A426

Evanoff K, Magasinski A, Yang J, Yushin G (2011) Adv Energy Mater 1:495-498

Fan X, Peng W, Li Y, Li X, Wang SS, Zhang S, Zhang F (2008) Adv Mater 20:4490-4493

Fernandez-Merino MJ, Guardia L, Paredes Jl, Villar-Rodil S, Fernandez PS (2010) Phys Chem C 114:6426-6432

Fredriksson H, Chakarov D, Kasemo B (2009) Carbon 47:1335-1342

Geim AK, Novoselov KS (2007) Nat 6:183-191
Gómez-Navarro C, Weitz RT, Bittner AM, Scolari M, Mews A, Burghard M, Kern K (2007) Nano Lett 7:3499-3503

Huang H, Faulkner T, Barker J, Saidi MY (2009) J Power Sources 189:748-751

Jiang K-C, Xin S, Lee JS, Kim J, Xiao XL, Guo YG (2012) Phys Chem Chem Phys 14:2934-2939

Katsnelson M, Novoselov KS, Geim AK (2006) Nat Phys 2:620-625

Kim H, Seo D, Kim S, Kim J, Kang K (2011) Carbon 49:326-332

Kim K-H, Jung D-W, Pham VH, Chung JS, Kong B-S, Lee JK, Kim K, Oh E-S (2012) Electrochim Acta 69:358-363

Kobayashi G, Nishimura SI, Park M-S, Kanno R, Yashima M, Ida T, Yamada A (2009) Adv Funct Mater 19:395-403

Levasseur S, Ménétrier M, Delmas C (2002) Chem Mater 14:3584-3590

Li D, Müller MB, Gilje S, Kan-er RB, Wallace GG (2008) Nat Nanotechnol 3:101-105

Li B, Cao H, Shao J, Li G, Qu M, Yin G (2011) Inorg Chem 50:1628-1632

Lian P-C, Zhu X-F, Liang S-Z, Li Z, Yang W-S, Wang H-H (2010a) Electrochim Acta 55:3909-3912

Lian PC, Zhu XF, Xiang HF, Li Z, Yang WS, Wang HH (2010b) Electrochim Acta $56: 834-840$

Lian P, Liang S, Zhu X, Yang W, Wang H (2011) Electrochim Acta 58:81-88

Liang S, Zhu X, Lian P, Yang W, Wang H (2011) I Solid State Chem 184:1400-1404

Liu H, Huang J, Li X, Liu J, Zhang Y, Du K (2012) Appl Surface Sci 258:4917-4921

Lu X, Yu M, Huang H, Ruoff RS (1999) Nanotechnology 10:269-271

Mai YJ, Wang XL, Xiang JY, Qiao YQ, Zhang D, Gu CD, Tu JP (2011) Electrochim Acta 56:2306-2311

Manev V, Banov B, Momchilov BA, Nassalevska A (1995) J Power Sources 57:99-103

Marzec J, Swierczek K, Przewo Znik J, Molenda J, Simon DR, Kelder EM, Schoonman J (2002) Solid State lonics 146:225-237

Mattevi C, Eda G, Agnoli S, Miller S, Mkhoyan KA, Celik O, Mastrogiovanni D (2009) Adv Funct Mater 19:2577-2583

Novoselov KS, Geim AK, Morozov SV (2004) Science 306:666-669

Pan AD, Choi D, Zhang JG, Liang JS, Cao G, Nie Z, Arey BW, Liu J (2011) J Power Sources 196:3646-3649

Prosini PP, Lisi M, Zane D, Pasquali M (2002) Solid State lonics 148:45-51

Rao CV, Reddy ALM, Ishikawa Y, Ajayan PM (2011) Appl Mater Interfaces 3:2966-2972

Shi S, Liu L, Ouyang C, Wang D-S, Wang Z, Chen L, Huang X (2003) Phys Rev B68:195108-195110

Shin HJ, Kim KK, Benayad A, Yoon SM, Park HK, Jung IS, Jin MH, Jeong HK, Kim JM, Choi JY, Lee YH (2009) Adv Funct Mater 19:1987-1992

Simon P, Gogotsi Y (2008) Nat Mater 7:845-848

Stankovich S, Dikin DA, Piner RD, Kohlhaas KA, Kleinhammes A, Jia Y, Wu Y, Nguyen ST, Ruoff RS (2007) Carbon 45:1558-1565

Staudenmaier L, Deut B (1898) Chem Ges 31:1481-1499

Stoller MD, Park S, Zhu Y, An J, Ruoff RS (2008) Nano Lett 8:3498-3502

Su C, Bu X, Xu L, Liu J, Zhang C (2012) Electrochim Acta 64:190-195

Tang B, Hu G (2012) J Power Sources 220:95-98

Tao L, Zai J, Wang K, Zhang H, Xu M, Shen J, Su Y, Qian X (2012) J Power Sources 202:230-235

Tarascon J-M, Armand M (2001) Nat 414:359-367

Tung VC, Allen MJ, Yang Y, Kaner RB (2009) Nat Nanotech 4:25-29

Wang JZ, Zhong C, Chou SL, Liu H-K (2010a) Electrochem Commun 12:1467-1470

Wang H-L, Cui L-F, Yang Y, Casalongue HS, Robinson JT, Liang Y-Y, Cui Y, Dai H-J, Am J (2010b) Chem Soc 132:13978-13980

Wang G, Bai J, Wang Y, Ren Z, Bai (2011a) J Scripta Mater 65:339-342

Wang G, Liu T, Luo Y-J, Tong X, Wan L-J, Zhao Y, Wang H, Ren Z-Y, Bai J-B (2011b) J Alloys Compd 509:216-220

Wintterlin J, ML B (2009) Surf Sci 603:1841-1852

Wolfenstine J (1999) J Power Sources 79:111-113

Wu Z, Ren W, Wen L, Gao L, Zhao J, Chen Z, Zhou G, Li F, Cheng H (2010) ACS Nano 4:3187-3194

Yan J, Wei T, Qiao W, Shao B, Zhao Q, Zhang L, Fan Z (2010) Electrochim Acta 55:6973-6978

Yang S-P, Cui G-K, Pang S-P, Cao Q, Kolb U, Feng X-L, Maier J, Muellen K (2010) Progress Chem 3:236-239

Yu X-Z, Huang C-G, Jozwiak CM, Köhl A, Schmid AK, Lanzara A (2011) J Electron Spectrosc Relat Phenom 184:100-103 
Yu F, Zhang J, Yang Y, Song G (2012) J Solid State Electrochem 159:A1573-A1578

Zhao X, Hayner CM, Hung HH (2011) J Mater Chem 21:17297-17303

Zhu X, Zhu Y, Murali S, Stoller MD, Ruoff RS (2011) J Power Sources 196:6473-6477

Zhu J-P, Xu Q-B, Zhao JJ, Yang G (2012) J Nanosci Nanotechnol 12:2534-2538

Zhu J-P, Zu W, Yang G, Song Q-F (2014) Mater Lett 115:237-240

doi:10.1186/2193-1801-3-585

Cite this article as: Zhu et al:: The application of graphene in lithium ion

battery electrode materials. SpringerPlus 2014 3:585.

Submit your manuscript to a SpringerOpen ${ }^{\circ}$ journal and benefit from:

- Convenient online submission

- Rigorous peer review

- Immediate publication on acceptance

- Open access: articles freely available online

- High visibility within the field

- Retaining the copyright to your article

Submit your next manuscript at $\boldsymbol{\nabla}$ springeropen.com 